\title{
EFECTO DE LA EDAD DE LAS REPRODUCTORAS SOBRE EL PESO DEL HUEVO, FERTILIDAD, INCUBABILIDAD Y PESO AL NACER DE LA CODORNIZ, VARIEDAD JAPONESA (COTURNIX COTURNIX JAPONICA)
}

\author{
Carlos Lembcke C. ${ }^{1}$, Edgardo Figueroa T. ${ }^{2}$, Patricia Sulca $A_{0}{ }^{2}$ y Néstor Falcón $P^{3}$
}

\begin{abstract}
Effect of breeding age on egg weight, fertility, hatchability and hatch weight in Japanese quail (Coturnix coturnix japonica).
\end{abstract}

The objective of this study was to evaluate the effect of breeding age on reproductive parameters (egg weight, fertility, hatchability and hatch weight) in Japanese quail (Coturnix coturnix japonica). A total of 300 eggs, from 3 different breeders (100 each), produced by birds at 5,10 and 15 months of age were incubated. Hatchability was $68 \%, 82 \%$ and $69 \%$ at 5,10 and 15 months, with fertility rates of $90 \%, 95 \%$ and $92 \%$. Egg $(12.29 \pm 1.64 \mathrm{~g})$ and hatch weights $(8.22 \pm 1.84 \mathrm{~g})$ were significantly greater ( $\mathrm{p}<0.05)$ for the 10-month-old birds. A positive correlation between egg weight and hatch weight averages was found for all three flocks, with $r=0.942$ for 10 month, $\mathrm{r}=0.863$ for 5 month and $\mathrm{r}=0.821$ for 15 month old birds. Embryo mortality was greatest at $15(23 \%)$ and $5(22 \%)$ months, compared to 10 months (13\%).

Key words: Japanese quail, hatchability, fertility, egg weight, hatch weight, breeding age, embryo mortality.

El objetivo del presente trabajo fue evaluar el efecto de la edad de las reproductoras sobre los parámetros reproductivos (peso del huevo, incubabilidad, fertilidad y peso al nacer) en codornices japonesas (Coturnix coturnix japónica). Con este fin se incubaron 300 huevos provenientes de tres lotes reproductores de 5, 10 y 15 meses de edad. La incubabilidad encontrada fue de $68 \%, 82 \%$ y $69 \%$ respectivamente. La fertilidad fue $90 \%, 95 \%$ y $92 \%$ respectivamente. Los promedios del peso del huevo y los promedios del peso al nacer de las cotobebe obtenidos, muestran diferencias estadísticamente significativas $(\mathrm{p}<0.05)$, siendo el lote 2 ( 10 meses) el que presenta los mayores pesos $(12.29 \mathrm{~g} \pm 1.64$ huevo y $8.22 \mathrm{~g} \pm 1.84$ al nacer). También se pudo observar que existe una correlación positiva entre los promedios del peso de huevo incubable y el peso al nacer, para los tres lotes, siendo la correlación más alta $\mathbf{r}=0.942$ observada en el lote 2 ( 10 meses); obteniéndose en el lote 1 ( 5 meses) y lote 3 ( 15 meses), correlaciones de $\mathrm{r}=$ 0.863 y $r=0.821$ respectivamente. Se obtuvo mayores porcentajes de mortalidad embrionaria en los lotes 1 ( 5 meses) y 3 ( 15 meses) siendo éstos de $22 \%$ y $23 \%$ respectivamente, y una menor mortalidad embrionaria de $13 \%$ en el lote 2 ( 10 meses).

Palabras clave: Codorniz japonesa, incubabilidad, fertilidad, peso del huevo, pesoal nacer, efecto de la edad, mortalidad embrionaria.

\footnotetext{
${ }^{1}$ Práctica privada.

${ }^{2}$ Laboratorio de Patología Aviar y Producción Avícola FMV - UNMSM.

${ }^{3}$ Laboratorio de Medicina Veterinaria Preventiva FMV - UNMSNM.
} 


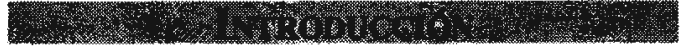

La codorniz presenta particularidades que la distinguen de cualquier otra gallinácea conocida. En esta especie el desarrollo embrionario es rápido, diecisiete días aproximadamente, la puesta es precoz y los individuos son adultos a la sexta semana de edad, en promedio. En condiciones adecuadas de iluminación, el porcentaje de puesta es de $80 \%$, logrando aproximadamente 300 huevos por año para cada ponedora en promedio (Lucotte, 1990).

A fines de la década de los ochenta comienza ha generalizarse la preferencia de alimentos bajos en contenido de calorías, grasa y colesterol; es precisamente ahí donde el huevo de codomiz surge como una alternativa interesante, debido a sus características. El huevo de la codorniz es un alimento completo, contiene todos los elementos nutritivos que requiere el hombre, es rico en vitaminas y en aminoácidos básicos; esto añadido a la fácil digestibilidad de sus albúminas y grasas constituye un elemento de alto valor en la dieta humana. Es adecuado para la alimentación de niños y ancianos, y de gran ayuda aportando elementos indispensables en la dieta de convalecientes. En el Oriente se emplea para curar ciertas enfermedades carenciales como el raquitismo, la anemia y deficiencias de crecimiento en los niños (Bissoni, 1993).

En el Perú la crianza de codornices se realiza con doble propósito, producción de carne y de huevos, surgiendo así como alternativa importante a la gran demanda existente de productos con alto contenido proteico destinados a la alimentación humana. Debido a la poca información técnica que existe en nuestro medio sobre la crianza de codornices, dado que la coturnicultura se esta convirtiendo en una industria importante en nuestro país, lo que se pretende es dar a conocer información que sirva como referencia para optimizar la crianza de dichas aves.
En el presente trabajo se pretende determinar la relación que existe entre la edad de las reproductoras, el peso del huevo, la incubabilidad, la fertilidad, y el peso al nacer de la codorniz

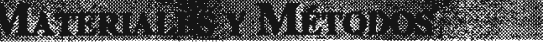

El presente trabajo de investigación se realizó en las instalaciones de la Granja Modelo de la Unidad del Laboratorio de Patología Aviar y Producción Avícola de la Facultad de Medicina Veterinaria - Universidad Nacional Mayor de San Marcos.

Se emplearon codornices japonesas (Coturnix coturnix japónica) reproductoras de 5, 10 y 15 meses de edad (42 hembras y 14 machos), en aparente buen estado de salud. La codornices fueron criadas en jaulas y alimentadas con un alimento preparado con una fórmula especial para reproductoras. El cambio de agua y la recolección de huevos se realizó dos veces/día.

Se dispuso de 3 lotes de aves, de diferente edad, en reproducción; así los lotes fueron de 5 (L1), 10 (L2) y 15 meses (L3) de edad de las reproductoras (Cuadro1).

Los huevos de los lotes L1, L2 y L3 se recolectaron y se colocaron en bandejas portahuevos con el polo menor hacia abajo. Los huevos que presentaron roturas y fisuras fueron eliminados, también aquéllos de aspecto irregular.

Siguiendo la recomendación de no almacenar los huevos más de 7 días (Bissoni, 1993). Los huevos se almacenaron en una habitación fresca y con poca luz; en promedio entre 3 a 4 días.

Antes de la carga en la incubadora, los huevos fueron pesados y marcados para diferenciar los lotes, y se ubicaron luego en la sala de incubación, manteniéndoseles por un tiempo de 12 horas ( fase de precalentamiento). Luego se desinfectaron por asper- 
sión, con un desinfectante comercial, momentos antes de incubar. Por último fueron cargados en la incubadora cuando ésta alcanzó una temperatura de $99.5^{\circ} \mathrm{F}\left(37.5^{\circ} \mathrm{C}\right)$ y una humedad de bulbo húmedo de $87^{\circ} \mathrm{F}\left(30^{\circ} \mathrm{C}\right)$ estas condiciones de temperatura y humedad se mantuvieron durante toda la incubación.

Los huevos fueron llevados a la nacedora el día 15 de incubación. Aquí se aumentó la humedad a $90^{\circ} \mathrm{F}\left(32^{\circ} \mathrm{C}\right)$. Para el proceso de secado del plumón se dejaron las cotobebes 8 horas más dentro de la nacedora. Finalmente se procedió al pesaje de cada cotobebe dentro de la sala de nacimientos.

Se pesaron los 300 huevos incubables antes de su carga a la incubadora esto se hizo mediante la ayuda de una balanza de $0.1 \mathrm{~g}$ de precisión, los pesos fueron registrados en fichas individuales (una ficha/grupo).

Se pesaron los cotobebes al primer día de nacidos, esto se hizo mediante la ayuda de una balanza de 0.1 gramos de precisión, los pesos fueron registrados en fichas individuales y la fertilidad y mortalidad embrionaria se determinó mediante embriodiagnosis; al finalizar el nacimiento se abrieron todos los huevos que no había eclosionado y se observó si estaban vacíos (infertiles) o si tenían embriones en desarrollo y en que etapa de desarrollo se encontraban de este modo se determinó también la causa de la mortalidad embrionaria.

El porcentaje se determinó de la siguiente manera:

Fertilidad, $\%=100-$ (número infértiles :tamaño de la muestra) x 100 .

La incubabilidad se estimó de dos maneras:

Incubabilidad, $\%=$ (número incubados $\div$ número Cargados) x 100.
Incubación de fértiles, $\%=(\%$ incubabilidad

$\div \%$ fertilidad) $\times 100$

Los parámetros obtenidos fueron ingresados a una base de datos para ser analizados mediante el uso del programa estadístico SYSTAT.

Se determinó que la variable cuantitativa continua seguía la distribución normal utilizando la prueba de Kolmogorov Smirnov de una muestra. Como la variable seguía la distribución normal se empleó la prueba de Análisis de varianza de una sola vía para establecer las diferencias estadísticas.

La definición de diferencias entre lotes se realizó con la prueba de comparación múltiple de medias, DMS Fisher Protegido. Los resultados se presentan expresados en medias e intervalos de confianza.

La incubabilidad y la fertilidad se evaluaron mediante diferencia de proporciones.

Para determinar la relación que hay entre el peso del huevo y el peso al nacer de la codorniz se uso la prueba de correlación de Pearson.

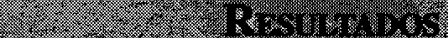

Los promedios del peso del huevo incubable y los promedios del peso al nacer de las cotobebe obtenidos en los diferentes lotes, mostraron diferencias estadísticamente significativas ( $\mathrm{p}<0.05)$, siendo el lote $2(10$ meses) el que presentó un mayor peso (Cuadro 2 y 3 respectivamente).

También se pudo observar que existe una correlación positiva entre los promedios del peso de huevo incubable y el peso al nacer de la codorniz japonesa, para los tres lotes, siendo la correlación más alta $r=0.942$ 
observada en el lote 2 (10 meses); obteniéndose en el lote 1 (5meses) y lote $3(15$ meses), correlaciones de $\mathrm{r}=0.863 \mathrm{y} \mathrm{r}=0.821$, respectivamente.

En lo que se refiere a la incubabilidad, incubabilidad de fértiles y fertilidad se observó el mayor porcentaje en el segundo lote (10 meses), siendo menores y muy similares los porcentajes observados en el primer (5 meses) y tercer lote( 15 meses) (Cuadros 4,5 y 6 respectivamente).

Se obtuvo mayores porcentajes de mortalidad embrionaria en los lotes $1(5 \mathrm{me}-$ ses) y 3 ( 15 meses), y una menor mortalidad embrionaria en el lote 2 (10 meses), como se observa en el Cuadro 7. También se pudo observar que el mayor porcentaje de mortalidad embrionaria se presentó en el primer tercio del desarrollo embrionario (Cuadro 8).

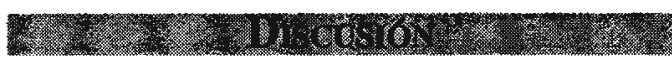

En primer lugar en lo referente a la relación entre la edad de las reproductoras y el peso del huevo incubable se pudo observar una diferencia estadística significativa entre los lotes, siendo el lote 2 (10 meses) el que presentó el mayor promedio de peso $(12.29 \mathrm{~g})$; de esto se puede deducir que la edad de las reproductoras influye en el peso del huevo incubable.

Cuadro 1. Grupos Experimentales.

\begin{tabular}{ccc}
\hline GRUPO & $\begin{array}{c}\text { EDAD DE LAS } \\
\text { REPRODUCTORAS }\end{array}$ & $\begin{array}{c}\text { CANTIDAD DE } \\
\text { HUEVOS }\end{array}$ \\
\hline LOTE 1 (L1) & 05 meses & 100 \\
LOTE 2(L2) & 10 meses & 100 \\
LOTE 3 (L3) & 15 meses & 100 \\
\hline
\end{tabular}

Cuadro 2. Promedio de Peso del huevo incubable ( $\mathrm{g}$ ) en codomices japonesas de diferentes edades.

\begin{tabular}{ccc}
\hline \multirow{2}{*}{$\begin{array}{c}\text { Edad de las } \\
\text { reproductoras }\end{array}$} & \multicolumn{2}{c}{ Peso huevo incubable } \\
\cline { 2 - 3 } & $\mathrm{N}$ & $\overline{\mathbf{X}} \pm \mathbf{I C}$ \\
\hline$(\mathrm{L} 1)$ & 100 & $11.95 \pm 1.695^{\mathrm{a}}$ \\
$(\mathrm{L} 2)$ & 100 & $12.29 \pm 1.642^{\mathrm{b}}$ \\
$(\mathrm{L} 3)$ & 100 & $12.11 \pm 1.711^{\mathrm{a}}$ \\
\hline
\end{tabular}

${ }^{\mathrm{a}-\mathrm{b}}$ Letras diferentes en columna muestran diferencias estadísticas significativas $(\mathrm{P}<0.05)$ 
Cuadro 3. Promedio de Peso al nacer (g) en Codornices japonesas nacidas de lotes Reproductores de diferentes edades.

\begin{tabular}{ccc}
\hline \multirow{2}{*}{$\begin{array}{c}\text { Edad de las } \\
\text { Reproductoras }\end{array}$} & \multicolumn{2}{c}{ Peso Cotobebe } \\
\cline { 2 - 3 }$(\mathrm{L} 1)$ & 68 & $\overline{\mathbf{X}} \pm \mathbf{I C}$ \\
\hline (L2) & 82 & $7.73 \pm 1.096^{\mathrm{a}}$ \\
(L3) & 69 & $8.22 \pm 1.484^{\mathrm{b}}$ \\
\hline $\mathrm{a}-\mathrm{b}$ Letras diferentes en columna muestran diferencias estadísticas significativas $(\mathrm{P}<0.05)$
\end{tabular}

Cuadro 4. Incubabilidad (\%) presentada en codornices japonesas de diferentes edades.

\begin{tabular}{cccc}
\hline EDAD DE LAS & \multicolumn{3}{c}{ INCUBABILIDAD (\%) } \\
\cline { 2 - 4 } REPRODUCTORAS & n & $\begin{array}{c}\text { Huevos } \\
\text { Eclosionados }\end{array}$ & $\% \pm$ IC \\
\hline (L1) & 100 & 68 & $68 \pm 9.14^{\mathrm{a}}$ \\
(L2) & 100 & 82 & $82 \pm 7.53^{\mathrm{b}}$ \\
(L3) & 100 & 69 & $69 \pm 9.06^{\mathrm{a}}$ \\
\hline
\end{tabular}

${ }^{a-b}$ Letras diferentes en columna muestran diferencias estadísticas significativas $(P<0.05)$

Cuadro 5. Incubabilidad de huevos fértiles (\%) presentada en codornices japónicas de diferentes edades.

\begin{tabular}{cccc}
\hline \multirow{2}{*}{ EDAD DE LAS } & \multicolumn{3}{c}{ Incubabilidad de Fértiles(\%) } \\
\cline { 2 - 4 } & $\begin{array}{c}\text { Huevos } \\
\text { Fértiles } \\
\text { n }\end{array}$ & $\begin{array}{c}\text { Huevos eclosionados } \\
\text { n }\end{array}$ & $\% \pm$ IC \\
\hline (L1) & 90 & 68 & $75.55 \pm 8.88^{\mathrm{a}}$ \\
(L2) & 95 & 82 & $86.23 \pm 6.91^{\mathrm{b}}$ \\
(L3) & 92 & 69 & $75.00 \pm 8.85^{\mathrm{a}}$ \\
\hline
\end{tabular}

${ }^{\mathrm{a}-\mathrm{b}}$ Letras diferentes en columna muestran diferencias estadísticas significativas $(\mathrm{P}<0.05)$ 
Cuadro 6. Fertilidad (\%) presentada en codornices japonesas de diferentes edades.

\begin{tabular}{cccc}
\hline \multirow{2}{*}{$\begin{array}{c}\text { EDAD DE LAS } \\
\text { REPRODUCTORAS }\end{array}$} & \multicolumn{3}{c}{ FERTILIDAD(\%) } \\
\cline { 2 - 4 } & $\begin{array}{c}\text { Total } \\
\text { Huevos } \\
\mathbf{n}\end{array}$ & $\begin{array}{c}\text { Huevos Fértiles } \\
\mathbf{n}\end{array}$ & $\% \pm$ IC \\
\hline (L1) & 100 & 90 & $90 \pm 5.88^{\mathrm{a}}$ \\
(L2) & 100 & 95 & $95 \pm 4.27^{\mathrm{b}}$ \\
(L3) & 100 & 92 & $92 \pm 5.32^{\mathrm{a}}$
\end{tabular}

$\overline{\mathrm{a}-\mathrm{b}}$ Letras diferentes en columna muestran diferencias estadísticas significativas $(\mathrm{P}<0.05)$

Cuadro 7. Mortalidad Embrionaria (\%) presentada en codornices japonesas de diferentes edades.

\begin{tabular}{cccc}
\hline EDAD DE LAS & \multicolumn{3}{c}{ MORTALIDAD EMBRIONARIA (\%) } \\
\cline { 2 - 4 } REPRODUCTORAS & $\begin{array}{c}\text { Total de } \\
\text { huevos } \\
\mathbf{n}\end{array}$ & $\begin{array}{c}\text { Muertes } \\
\text { Embrionarias }\end{array}$ & $\% \pm$ IC \\
\hline (L1) & 100 & 22 & $22 \pm 8.12^{\mathrm{a}}$ \\
(L2) & 100 & 13 & $13 \pm 6.59^{\mathrm{b}}$ \\
(L3) & 100 & 23 & $23 \pm 8.25^{\mathrm{a}}$ \\
\hline
\end{tabular}

${ }^{a-b}$ Letras diferentes en columna muestran diferencias estadísticas significativas $(P<0.05)$

Cuadro 8. Mortalidad Embrionaria en los diferentes tercios de desarrollo del embrión en codornices japonesas.

\begin{tabular}{ccccc}
\hline EDAD DE LAS & \multicolumn{4}{c}{ Muertes embrionarias } \\
\cline { 2 - 5 } REPRODUCTORAS & $\begin{array}{c}\text { Primer } \\
\text { tercio }\end{array}$ & $\begin{array}{c}\text { Segundo } \\
\text { tercio }\end{array}$ & $\begin{array}{c}\text { Tercer } \\
\text { tercio }\end{array}$ & $\begin{array}{c}\text { Total } \\
\text { muertes }\end{array}$ \\
\hline (L1) & 9 & 4 & 9 & 22 \\
$(\mathrm{~L} 2)$ & 10 & 1 & 2 & 13 \\
$(\mathrm{~L} 3)$ & 17 & 2 & 4 & 23 \\
\hline TOTAL & 36 & 7 & 15 & 58 \\
\hline
\end{tabular}


Los pesos obtenidos en el presente trabajo están por encima de los obtenidos por otros autores. Lucotte (1990) encontró un peso promedio del huevo incubable en codornices de $10 \mathrm{~g}$ Bissoni (1993) de $9.6 \mathrm{~g}$ Quintana (1991) encontró que el peso promedio del huevo incubable óptimo para la selección en codornices de $10.5 \mathrm{~g}$ a $12 \mathrm{~g}$ Los mayores pesos obtenidos en el presente estudio pueden ser debidos a una mejora genética conseguida durante los últimos años.

Algo similar a lo obtenido con el peso del huevo incubable se obtuvo de la relación entre la edad de las reproductoras y el peso al nacer del cotobebe se observó una diferencia estadística significativa entre los lotes, siendo el segundo lote ( 10 meses) el que presentó el mayor promedio de peso al nacer, siendo este de $8.223 \mathrm{~g}$; observándose aquí también la influencia de la edad de las reproductoras.

Igualmente el peso al nacer encontrado en este trabajo fue superior al promedio que mencionan Bissoni (1993) que está entre 6-8 g y Quintana (1991) de 7.5g; este último también menciona que los animales seleccionados como reproductores deben tener un peso al nacer superior a $7 \mathrm{~g}$.

Existe una correlación entre el peso del huevo incubable y el peso al nacer del cotobebe con grado de asociación fuerte para los tres lotes, siendo $r=0.942$ la mayor correlación la cual se obtuvo en el segundo lote (10 meses).

Estos resultados muestran una mejor correlación que la obtenida por Sharma y Panda (1979), en codornices quienes obtuvieron una correlación de $0.66-0.87$ entre el peso del huevo incubable y el peso al nacer del cotobebe. Sin embargo resultados similares fueron obtenidos por Nguyen y Sarda (1977), en gallinas Leghorn variedad blanca de cresta simple, quienes obtuvieron una correlación alta y significativa de 0.98 .
La incubabilidad y la incubabilidad de fértiles fueron mayores en el segundo lote (10 meses), siendo $82 \%$ y $86.32 \%$ respectivamente.

Resultados muy similares a los obtenidos en el presente trabajo son los presentados por Begin y Maclaury (1974), quienes trabajando con codornices de seis, diez y quince meses obtuvieron porcentajes de incubabilidad de $77.63 \%, 84.73 \%$ y $74.39 \%$ respectivamente. También en codornices, Chahil y Johnson (1974) trabajando con lotes de siete, ocho, nueve, diez y once meses de edad obtuvieron porcentajes de incubabilidad de $35.59 \%$, 47.49\%, $70.04 \%$, $64.51 \%$ y $66.25 \%$ respectivamente. Lucotte (1990) menciona un porcentaje de eclosión en codornices de $80 \%$. Bissoni (1993) encontró que el porcentaje de nacimientos en codornices era de 85\%. Estos resultados indican una variabilidad en los porcentajes de incubabilidad.

En trabajos reportados en gallinas reproductoras para producción de pollos de carne. Trabajando con lotes desde 7 hasta 16 meses se obtuvieron porcentajes de incubabilidad de fértiles entre $84.87 \%$ a 93.08\% (McDaniel y Brake, 1981; McDaniel, et al.,1979). Mostrando que las gallinas reproductoras de pollos de carne tienen mejores rendimientos productivos que las codornices y esto debido al intenso mejoramiento genético al que han sido sometidas este tipo de aves en la industria avícola durante las dos últimas décadas, cosa que no se ha dado en codornices.

El mayor porcentaje de fertilidad se obtuvo en el segundo lote (10 meses), este fue de $95 \%$.

Este resultado se puede considerar como muy bueno, por estar muy por encima a los encontrados por otros autores. Lucotte (1990) menciona una fertilidad en codornices de $80 \%$. Quintana (1991) encontró un porcentaje de fertilidad en codornices de 85 a 90\%. (Ottinger, et al., 1983) encontraron en 
codornices de 28, 56, 107 y 149 semanas de edad, que la incubabilidad y la fertilidad decae a partir de las 56 semanas hacia delante.

En trabajos realizados en gallinas reproductoras para producción de pollos de carne. McDaniel y Brake (1981) trabajando con lotes de siete, nueve y catorce meses obtuvieron un porcentaje de fertilidad de $95.55 \%, 94.2 \%$ y $88.4 \%$ respectivamente.

El mayor porcentaje de mortalidad embrionaria se presentó en el tercer lote( 15 meses) y el menor porcentaje en el segundo lote (10 meses) siendo este de 13\%. Durante el desarrollo embrionario el mayor porcentaje de mortalidad se presentó en el primer tercio; al igual que Lucotte (1990), el cual menciona que el mayor porcentaje de mortalidad embrionaria ocurre en el primer tercio de desarrollo del embrión.

Finalmente se puede ver que gran parte de los trabajos encontrados coinciden en señalar que la edad de las reproductoras influye en el comportamiento reproductivo de éstas, y el caso de la codorniz japonesa no es la excepción.

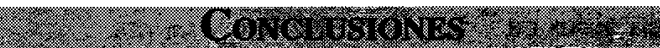

- El efecto de la edad de las reproductoras sobre los parámetros reproductivos (peso del huevo, incubabilidad, fertilidad y peso al nacer del cotobebe) en codorni-ces japonesas es significativo.

- Las reproductoras de 10 meses presentaron los mejores pesos y parámetros reproductivos.

- En todos los lotes se obtuvo una alta correlación entre el peso del huevo incubable y el peso al nacer del cotobebe.

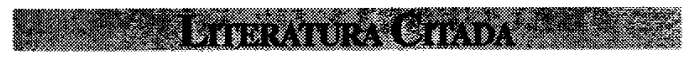

1. Begin, J.J. y D.W. Maclaury. 1974. "Age of breeder versus hatchability of fertile eggs in Coturnix Quail". Poultry Sci. 53(4): 1614-1616.

2. Bissoni E. 1993. "Cría de la codorniz". 2a Ed., p. 188. Editorial. Albatroz. Buenos Aires-Argentina.

3. Chahil, P. S. y W. A. Johnson. 1974. "Effect of preincubation storage, parental age and rate of lay on hatchability in Coturnix cotumix japonica". Poultry Sci. 53(2): 529-534.

4. Lucotte G. 1990. "La codorniz, Cría y Explotación". 2a ed. p. 200. Editorial Mundi Prensa. Madrid.

5. Mcdaniel, G. R. y J. Brake. 1981. "Factors affecting Broiler Breeder performance. 4. The interrelationship of some reproductive traits". Poultry Sci. 60(8): 1792-1797.

6. Mcdaniel, G.R.; D.A. Roland, y M.A. Coleman. 1979. "The effect of egg shell quality on hatchability and embryonic mortality”. Poultry Sci. 58(1): 10-12.

7. Nguyen, X. S. y R. Sarda. 1977. "Efecto del peso de los huevos en los resultados de la incubación". VI Memoria de la Asociación Latinoamericana de Producción Animal. La Habana, Cuba. Tomo II NR-14. 111 pp.

8. Ottinger, M. A.; C. S. Duchala, y M. Masson. 1983. "Age-related reproductive decline in the male Japanese quail". Horm Behav. 17(2): 197-207.

9. Quintana, J.A. 1991. "Manejo de las aves domésticas más comunes". 2 da ed. pp. 182-277. Editorial Trillas-México.

10. Sharma, G. L. y B. Panda. 1979. "Studies on some productive traits in Japanese Quail(Coturnix coturnix japónica). An. Breed. Abstr. 47(2) pp. 105. 